\title{
VALOR ADICIONADO E LUCRATIVIDADE DAS EMPRESAS LISTADAS NA REVISTA EXAME MAIORES E MELHORES NO PERÍODO DE 2007-2010 ${ }^{1}$
}

\section{ADDED VALUE AND PROFITABILITY OF COMPANIES LISTED IN THE REVISTA EXAME MAIORES E MELHORES IN THE PERIOD 2007-2010}

\author{
Jorge Eduardo Scarpin ${ }^{2}$ \\ Doutor em Controladoria e Contabilidade pela USP \\ Professor do Programa de Pós-Graduação em Ciências Contábeis da UFPR \\ jorge.scarpin@ufpr.br \\ Márcia Martins Mendes De Luca \\ Doutora em Controladoria e Contabilidade pela USP \\ Professora do Programa de Pós-Graduação em Administração e Controladoria da UFC \\ marciadeluca@ufc.br \\ Jacqueline Veneroso Alves da Cunha \\ Doutora em Ciências Contábeis pela USP \\ Professora do Programa de Pós-Graduação em Ciências Contábeis da UFMG \\ jvac@face.ufmg.br

\section{Lara Fabiana Dallabona} \\ Doutoranda em Ciências Contábeis e Administração pela FURB \\ Bolsista do Programa do Fundo de Apoio à Manutenção e ao Desenvolvimento da Educação Superior (FUMDES) \\ Professora da Universidade do Estado de Santa Catarina (UDESC) \\ lara.dallabona@udesc.br

\section{Vanessa Ingrid da Costa Cardoso} \\ Mestre em Administração e Controladoria pela UFC \\ Professora do Centro Universitário Estácio do Ceará \\ nessaingrid@gmail.com
}

\section{RESUMO}

No contexto corporativo há uma incessante busca pela lucratividade. Logo, a identificação dos fatores inerentes à melhoria dos resultados é fundamental para a tomada de decisão estratégica. Nesse sentido, percebe-se a potencialidade da Demonstração do Valor Adicionado (DVA) na gestão corporativa, tendo em vista que a mesma evidencia a criação e a distribuição da riqueza aos fatores que contribuíram para a criação de valor da empresa. Dessa forma, este estudo investiga a correlação da distribuição do valor adicionado aos agentes colaboradores na formação da riqueza e a lucratividade das empresas. Desenvolveu-se uma pesquisa descritiva, documental e quantitativa utilizando a correlação canônica. Os resultados demonstram que, em média, os setores analisados

\footnotetext{
${ }^{1}$ Artigo recebido em: 05/06/2014. Revisado por pares em: 07/08/2014. Recomendado para publicação em: 07/08/2014 por Orleans Silva Martins (Editor Geral). Publicado em: 31/08/2014. Organização responsável pelo periódico: UFPB.

2 Endereço: Av. Prefeito Lothário Meissner, 632, 1º andar, Campus III, Jardim Botânico, CEP 80.210-170, Curitiba/PR. DOI: $\underline{\text { http://dx.doi.org/10.18405/recfin20140201 }}$
} 
apresentaram grande disparidade da mediana para o período estudado. As combinações lineares, extraídas da correlação canônica, foram significantes (nível de 0,05) para todos os setores e anos, apresentando boas e fortes correlações, garantindo a proximidade dos indicadores analisados. Conclui-se que há correlação entre a distribuição do valor adicionado aos agentes colaboradores e a lucratividade das empresas nos setores analisados.

Palavras-chave: Valor Adicionado. Lucratividade. Maiores e Melhores Empresas.

\section{ABSTRACT}

In the corporative context, there is an incessant search for profitability. Therefore, the identification of factors inherent to the improvement of results is fundamental for strategic decision-making. It is important to remember that the measure of profit, when individually assessed is not enough for representing the success of a business and may lead managers into wrong conclusions. In this sense, it is possible to observe the potential of Added Value Demonstration in corporative management, since this potential reflects the outcome of business operations taking into consideration factors such as the creation and the distribution of wealth and factors, which contributed to the creation of company value. Thus, this study investigates the relation between added value distribution for employee agents in the production of wealth and profitability in companies. This descriptive, documental and quantitative research employs canonical correlation. The sample gathers 450 participating companies out of 1.216 major companies in terms of sales, according to the Revista Exame Maiores e Melhores, in 2011. The analysis comprehended data from financial years of 2007, 2008, 2009 and 2010. The results demonstrate that, on average, the analyzed sectors presented great differences in comparison to the studied period. The linear combinations, extracted from canonical correlation, have been significant (level 0.05) for all sectors and years, presenting good and strong correlations, which guaranteed the proximity of analyzed indicators. It has been concluded that there is correlation between added value for employee agents and profitability of companies in the sectors analyzed.

Keywords: Added Value. Profitability. Largest and Best Companies.

\section{INTRODUÇÃO}

A divulgação de informações sobre as atividades empresariais é tão importante quanto à lucratividade do seu negócio e a condição de permanência no cenário econômico. Hendriksen e Breda (1999) assinalam que a divulgação financeira deve fornecer informação útil para subsidiar decisões racionais de investimento e concessão de crédito, dentre outras, para os mais diversos usuários. Um disclosure de qualidade aumenta a precisão das informações sobre as decisões operacionais e de investimentos tomadas pelos gestores (BENS; MONAHAN, 2004) e pelos vários stakeholders, beneficiando os resultados do empreendimento. Nesse contexto, é relevante destacar, dentre os vários tipos de relatórios contábeis, a Demonstração do Valor Adicionado (DVA). Na visão de Santos (2003), a DVA se destaca como a forma mais competente criada pela Contabilidade para evidenciar a criação e a distribuição da riqueza aos fatores que contribuíram para sua criação.

A DVA é uma demonstração que apresenta a riqueza criada pela empresa e a remuneração aos agentes que contribuíram para essa criação (DE LUCA et al., 2009), seja por meio da infraestrutura política, macroeconômica e social necessária à sua operação (governo), pela utilização de esforços humanos (empregados), por cessão de bens e/ou recursos financeiros de terceiros (fornecedores), ou por seus recursos próprios (sócios e acionistas).

Segundo o Pronunciamento Técnico no 9 do Comitê de Pronunciamentos Contábeis (CPC), a distribuição da riqueza criada deve ser apresentada na DVA, de forma detalhada, levando em conta os seguintes itens: a) pessoal e encargos; b) impostos, taxas e contribuições; c) juros e aluguéis; d) juros sobre o capital próprio (JCP) e dividendos; e) lucros retidos/prejuízos do exercício 
(CPC, 2008). Nesse sentido, diversos estudos têm apresentado a relevância da DVA para análises econômicas e gerenciais, destacando-se aqueles que discorrem sobre a distribuição do valor adicionado aos vários agentes que colaboram na criação da riqueza (RODRIGUES JUNIOR, 2003; CUNHA; RIBEIRO; SANTOS, 2005; CHAN; SLOMSKI; MARTINS, 2007; CHAN; SILVA; MARTINS, 2007; BRAGA, 2008; SANTOS; SILVA, 2009; BOSCOV; BISPO, 2010).

Dentre as finalidades da DVA, Cosenza (2003) afirma que a demonstração permite o desenvolvimento de um efetivo sistema de avaliação de unidades e gestores, utiliza uma linguagem acessível a vários usuários e reflete a eficiência e a lucratividade das suas operações, bem como a evolução econômica em seu conjunto. Cabe destacar que a medida do lucro, quando analisada individualmente, é insuficiente para representar o sucesso de um negócio e pode levar os gestores a conclusões equivocadas, comprometendo o processo de tomada de decisões. Por isso, é importante que o resultado das operações de uma empresa seja avaliado sob vários aspectos (rentabilidade, produtividade, geração de riqueza, geração de valor, dentre outros).

Considerando os estudos anteriores sobre a DVA e a importância da medida do lucro nos negócios empresariais, este estudo procura responder ao seguinte questionamento: qual é a correlação entre o valor adicionado distribuído aos agentes colaboradores na formação da riqueza e da lucratividade das empresas? Nesse contexto, o estudo elege como objetivo geral identificar a correlação da distribuição do valor adicionado aos agentes colaboradores na formação da riqueza e a lucratividade das empresas. Para tanto, foram tratados os dados da DVA e os resultados auferidos no período de 2007 a 2010 de 450 empresas participantes de oito setores de atividades, conforme classificação da Revista Exame Maiores e Melhores de 2010.

Entendendo a busca da lucratividade como um dos desafios para o sucesso de qualquer negócio, visto que as empresas atuam em um mercado altamente competitivo e apresentam margens cada vez menores, o estudo se justifica na medida em que busca verificar a relação entre a distribuição da riqueza gerada pelas empresas aos agentes colaboradores na formação da riqueza e da sua lucratividade. Destaca-se, ainda, a contribuição do estudo no sentido de apresentar um novo olhar sobre a DVA ao buscar explicações da distribuição do valor adicionado para os resultados das empresas.

\section{REFERENCIAL TEÓRICO}

A Demonstração do Valor Adicionado (DVA) tornou-se obrigatória para as companhias abertas que atuam no mercado brasileiro de capitais a partir da aprovação da Lei $\mathrm{n}^{\mathbf{0}} 11.638$, em dezembro de 2007. A DVA está fundamentada em conceitos macroeconômicos, no entanto, existem diferenças temporais entre os modelos contábil e econômico no cálculo do valor adicionado. A Economia se baseia na produção, para o cálculo do Produto Interno Bruto (PIB), enquanto a Contabilidade utiliza o conceito de realização da receita, baseado no regime de competência (CPC, 2008). Surgida na década de 1970, a DVA evidencia a distribuição dos benefícios gerados pelos esforços da empresa entre os diversos stakeholders (empregados, governo, financiadores de capital próprio e de capital de terceiros).

As primeiras DVA foram divulgadas no Reino Unido, em meados dos anos 1970 (PONG; MITCHELL, 2005). No Brasil, os primeiros estudos sobre a DVA surgiram na década de 1990 (DE LUCA; 1991; 1996; SANTOS, 1999). Para De Luca (1998, p. 28) a Demonstração do Valor Adicionado (DVA) pode ser conceituada como "um conjunto de informações de natureza econômica. É um relatório contábil que visa demonstrar o valor da riqueza gerada pela empresa e a distribuição para os elementos que contribuíram para sua geração". A partir dessa definição, percebe-se que a referida demonstração proporciona aos usuários análises mais abrangentes, além das análises específicas, pois envolve vários agentes e apresenta informação que possibilita a implementação de práticas em busca da lucratividade e da criação de valor das empresas. 
Aspectos relacionados ao uso e ao papel da DVA são amplamente ressaltados por vários estudiosos, como Meek e Gray (1988) que destacaram sua utilidade como enfatizadora da interdependência entre os grupos de stakeholders. Morley (1979) atribui à demonstração a possibilidade de ser usada como meio de mensurar o tamanho e a importância da empresa e como ferramenta de avaliação dos agentes comprometidos com a entidade. Bentley (1981) também a destaca como uma ferramenta eficaz de avaliação da administração. Ainda, é atribuído à mesma, o papel de fornecedora de indicadores para diagnóstico e previsão (MORLEY, 1979; SANTOS, 2007) e de fornecedora de enfoques distintos de evidenciação numa mesma demonstração (RIAHI-BELKAOUI, 1999).

De acordo com Riahi-Belkaoui (1999), dentre as vantagens mais citadas do uso da DVA, comparativamente a outras demonstrações tradicionais (como balanço patrimonial, demonstração do resultado do exercício e demonstração do fluxo de caixa), destacam-se: (i) melhora do clima organizacional, favorecendo uma atitude positiva, principalmente por parte dos empregados; (ii) forma mais adequada de mensuração de bônus de produtividade; (iii) indicadores com melhor poder de predição, principalmente do lucro, retorno esperado e risco da empresa; (iv) estabelecimento de um elo entre a contabilidade e a economia; (v) o valor adicionado como uma métrica superior para avaliar a importância e o tamanho das empresas; (vi) instrumento de negociação trabalhista; (vii) avaliação de empresas multinacionais dentro do país; (viii) mensuração de desempenho; e (ix) indicador da eficiência dos gestores.

Diversos estudos, no cenário nacional e internacional, têm sido realizados com o objetivo de evidenciar sua aplicabilidade e utilidade, bem como de analisar seus dados. A experiência de publicação da DVA foi identificada por Mcleay (1983) em 32 empresas em mais de 200 pesquisas (francesas, alemãs, britânicas, holandesas, italianas, belgas, suecas, dinamarquesas, espanholas, canadenses e australianas). Já Burchell, Clubb e Hopwood (1985) mencionaram a existência de pesquisa sobre DVA na Alemanha, Holanda e França, além do Reino Unido. Cunha (2002) encontrou evidências de publicação no Chile, França e Portugal. Rutherford (1980) bem como Burchell, Clubb e Hopwood (1985) realizaram pesquisas para avaliar a experiência de publicação da demonstração no Reino Unido. Van Staden (1998, 2000 e 2007) estudou, em diversas ocasiões, a demonstração no contexto da África do Sul, onde é elevada a sua publicação. A partir dos estudos mencionados, verifica-se a abrangência da utilização da Demonstração do Valor Adicionado.

A utilidade da DVA foi verificada por meio da percepção de profissionais do mercado e da academia na Índia (RAO, 2001) e entre auditores, sindicatos de empregados, governo e estudantes em Joanesburgo (VAN STADEN, 1998). Já Consenza (2003) constatou sua utilidade no Brasil para o cálculo do PIB, na formação de indicadores que permitem a compreensão do papel dos agentes econômicos na formação da riqueza das empresas.

A relação da DVA, focada na carga tributária, foi um dos aspectos pesquisados por Hashimoto e Santos (2003), Gallon et al. (2006), Moraes (2008) e Tinoco e Moraes (2008). Lima (2003), Vicente (2003), Silveira (2003), Zan (2004), Pinto (2005), Santos, Chan e Silva (2007), Vieira e Santos (2007), Braga (2008), Morch et al. (2008), Bispo (2009), Fregonesi (2009) e Machado et al. (2009), que estudaram a DVA quanto à geração e distribuição de riqueza em oportunidades e setores específicos no cenário brasileiro como, por exemplo, após um período de inúmeras privatizações.

A demonstração também foi discutida sob o mérito de fornecimento de indicadores numéricos para análises específicas (RIAHI-BELKAOUI; FREKAT, 1994; RIAHI-BELKAOUI; PICUR, 1994; BAO; BAO, 1996; CHAN, MARTINS; SLOMSKI, 2003; KROETZ; COSENZA, 2003; DALMÁCIO, 2004). Portanto, observa-se que a evidenciação das informações contempladas pela DVA dispõe ferramentas estratégicas valiosas, uma vez que subsidiam as diversas tomadas de decisão dos usuários, tanto internos quanto externos. Vale reconhecer ainda que as informações estão associadas a diversos fatores da gestão empresarial, pois envolve os vários agentes que contribuem para a 
criação da riqueza da empresa e podem implicar em atitudes mais embasadas por parte dos stakeholders.

Um dos aspectos fundamentais desta demonstração consiste no disclosure do valor adicionado distribuído para cada um dos agentes responsáveis por sua conquista, revelando a parte que coube a cada um dos responsáveis pela conquista da riqueza na organização. Nesse contexto, a partir da DVA, os colaboradores das empresas podem realizar avaliações periódicas sobre a situação destas e identificar o quanto contribuíram para o seu resultado. O presente estudo se encontra focado nesse aspecto, ao investigar especificamente a relação entre o valor adicionado distribuído aos agentes colaboradores e a lucratividade das empresas.

\section{ASPECTOS METODOLÓGICOS}

Considerando o objetivo de identificar o poder explicativo da distribuição do valor adicionado aos agentes sobre a lucratividade das empresas, esta pesquisa se caracteriza como descritiva, documental e quantitativa. A população e a amostra estimada para o desenvolvimento do estudo, bem como os procedimentos de coleta e análise de dados, são descritos a seguir.

\subsection{População, amostra e procedimentos de coleta e análise de dados}

O estudo utilizou como população alvo a listagem das 1.216 maiores empresas em volume de vendas, extraídas do sitio da Revista Exame Maiores e Melhores, em outubro de 2011, considerando vinte e um setores econômicos específicos. O período analisado foi de quatro anos, compreendendo os dados dos exercícios financeiros de 2007, 2008, 2009 e 2010. Foram considerados para a coleta de dados os indicadores econômicos e financeiros disponíveis no website da Revista, diretamente relacionados à Demonstração do Valor Adicionado (DVA) das empresas. Os indicadores são detalhados no item 3.2 desta seção.

Para seleção da amostra foram considerados os setores com mais de 50 observações, pois entende-se que os setores com número maior de observações trazem mais qualidade à pesquisa empírica. Esse critério também foi observado na estatística descritiva, visto que em determinados períodos só havia uma empresa que dispunha de todos os dados, dificultando a diferença entre média, mediana e desvio padrão. Dessa forma, foram identificadas 450 empresas que fizeram parte da amostra da pesquisa, considerando oito setores de atividades, conforme descrito na Tabela 1.

Tabela 1 - Descrição da população e amostra por setor de atividade

\begin{tabular}{lccc}
\hline Setores Econômicos de Atividades & População & Amostra & \% da amostra em relação à população \\
\hline Atacado & 84 & 51 & 60,7 \\
Bens de Consumo & 102 & 64 & 62,7 \\
Produção Agropecuária & 105 & 63 & 60,0 \\
Química e Petroquímica & 73 & 50 & 68,5 \\
Varejo & 107 & 64 & 59,8 \\
Indústria da Construção & 84 & 59 & 70,2 \\
Energia & 153 & 99 & 64,7 \\
\hline Total & $\mathbf{7 0 8}$ & $\mathbf{4 5 0}$ & $\mathbf{6 3 , 6}$ \\
\hline
\end{tabular}

Fonte: dados da pesquisa.

É relevante destacar que a Tabela 1 apresenta apenas a população dos setores de atividades que foram objeto de análise (708 empresas), e a amostra contempla a quantidade efetiva de empresas que fez parte da estatística descritiva e cálculo da correlação canônica.

Dentre as observações analisadas, optou-se por utilizar os indicadores: lucro líquido legal; riqueza criada; número de empregados; riqueza criada por empregados; e salários e encargos. A contextualização dos indicadores e os grupos de análise para o cálculo da correlação canônica são descritos a seguir. 


\subsection{Contextualização dos indicadores do Grupo A e Grupo B}

Os indicadores utilizados para análise e desenvolvimento do estudo estão relacionados à demonstração do valor adicionado (DVA) e foram distribuídos em dois grupos (Grupo A e Grupo B). No Grupo A foram utilizados três indicadores: (i) riqueza criada por empregado; (i) número de empregados; e (iii) salários e encargos do respectivo período em análise. Para o Grupo B foram utilizados outros dois indicadores: (iv) o lucro líquido legal e a (v) riqueza criada pela empresa durante o respectivo período. Nesse caso, buscou-se identificar o poder explicativo da distribuição do valor adicionado aos agentes sobre a lucratividade das empresas, conforme enunciado no objetivo geral. Os indicadores são descritos no Quadro 1.

Quadro 1 - Descrição dos indicadores

\begin{tabular}{|c|l|}
\hline $\begin{array}{c}\text { Indicadores/ } \\
\text { Variáveis }\end{array}$ & \multicolumn{1}{c|}{ Descrição dos indicadores } \\
\hline $\begin{array}{c}\text { Lucro líquido } \\
\text { legal }\end{array}$ & $\begin{array}{l}\text { É o resultado nominal do exercício, apurado de acordo com as regras legais (sem considerar os } \\
\text { efeitos da inflação), depois de descontada a provisão para o imposto de renda e a contribuição } \\
\text { social e ajustados os juros sobre o capital próprio, considerados como despesas financeiras } \\
\text { (EXAME, 2012). }\end{array}$ \\
\hline Riqueza criada & $\begin{array}{l}\text { Representa toda a contribuição auferida pela empresa no decorrer de determinado período, para a } \\
\text { formação do Produto Interno Bruto (PIB) do país, já deduzida a depreciação (EXAME, 2012). }\end{array}$ \\
\hline $\begin{array}{c}\text { Número de } \\
\text { empregados }\end{array}$ & $\begin{array}{l}\text { Geralmente é utilizado para identificar quanto cada um contribui na geraça de riqueza das em- } \\
\text { presas, considerando a média geral. Destaca-se, portanto, que mesmo com rotatividade de pesso- } \\
\text { al, o empregado contribui, em determinados momentos, para a geração de riqueza da empresa } \\
\text { (SANTOS, 2007). }\end{array}$ \\
\hline $\begin{array}{c}\text { Riqueza criada } \\
\text { por empregado }\end{array}$ & $\begin{array}{l}\text { É calculado por meio da riqueza criada, dividido pela média aritmética do número de emprega- } \\
\text { dos que a empresa apresenta no exercício findo, excluindo os eventuais serviços terceirizados. } \\
\text { Indica a produtividade auferida pelos empregados e a respectiva contribuição média individual } \\
\text { por empregado na riqueza gerada (EXAME, 2011). }\end{array}$ \\
\hline $\begin{array}{c}\text { Salários e } \\
\text { encargos }\end{array}$ & $\begin{array}{l}\text { Buscam representar o valor destinado ao pagamento de mão de obra dos colaboradores. Tal indi- } \\
\text { cador é obtido dividindo-se o valor adicionado pelos gastos com pessoal. Sendo assim, a informa- } \\
\text { ção desses gastos com pessoal representa quanto de riqueza criada pela organização destinou-se } \\
\text { aos seus trabalhadores (SANTOS, 2007). }\end{array}$ \\
\hline
\end{tabular}

Fonte: Exame (2012) e Santos (2007).

Destaca-se que esses indicadores poderiam ser identificados como variáveis dependentes e independentes, porém, quando se aplica a correlação canônica, ambos os indicadores não são considerados dependentes ou independentes, pois nesse cálculo a relevância está na busca por explicações para a natureza de quaisquer relações existentes entre o conjunto de variáveis analisadas (HAIR JR et al., 2005), como é o caso deste estudo.

\section{DESCRIÇÃO E ANÁLISE DOS RESULTADOS}

Esta seção descreve os resultados encontrados diante os dados analisados. Para simplificar a apresentação dos dados por meio de tabelas, optou-se por demonstrar os indicadores utilizados em números arábicos, em que o indicador I demonstra o lucro líquido legal; o indicador II, a riqueza criada; o indicador III, o número de empregados; e os indicadores IV e V, a riqueza criada por empregado e os salários e encargos, respectivamente, para a descrição da estatística descritiva.

Observa-se por meio dos dados dispostos na Tabela 2, que a média dos indicadores analisados no decorrer dos quatro anos apresentou grande disparidade se considerada a distribuição, com um alto coeficiente de variação para os indicadores e anos de análise. Além disso, considerase que quanto maior a disparidade dos valores obtidos entre a média e a mediana, maior será o desvio padrão destes dados, ou seja, em todos os indicadores analisados, bem como em todos os períodos, a média e a mediana não ficaram próximas, indicando uma diferença entre os valores de máximo e de mínimo, evidenciando a existência de diferenças no perfil das empresas analisadas. 
Tabela 2 - Estatísticas descritivas do setor de atacado.

\begin{tabular}{|c|c|c|c|c|c|c|}
\hline \multirow{2}{*}{ Estatística } & \multirow{2}{*}{$\begin{array}{c}\text { Setor } \\
\text { Indicador }\end{array}$} & \multicolumn{5}{|c|}{ Atacado } \\
\hline & & $\mathbf{I}$ & II & III & IV & V \\
\hline \multirow{4}{*}{ Média } & 2010 & 17,92 & 84,3 & 880,9 & 177,3 & 19,09 \\
\hline & 2009 & 48,99 & 351,2 & 1083 & 215,4 & 33,48 \\
\hline & 2008 & 31,41 & 389,4 & 1168 & 318,9 & 41,16 \\
\hline & 2007 & 962,4 & 5508 & 24174 & 4222 & 1025 \\
\hline \multirow{4}{*}{ Mediana } & 2010 & 9,35 & 47,85 & 373 & 112,3 & 9,15 \\
\hline & 2009 & 8,8 & 47,2 & 340 & 55,6 & 7,8 \\
\hline & 2008 & 8,45 & 57,75 & 435 & 71,5 & 8,7 \\
\hline & 2007 & 19,65 & 86,6 & 1461 & 134 & 26,5 \\
\hline \multirow{4}{*}{ Desvio padrão } & 2010 & 22,58 & 82,79 & 1488 & 232 & 20,27 \\
\hline & 2009 & 180,4 & 1509 & 1623 & 512,1 & 81,41 \\
\hline & 2008 & 181,1 & 1438 & 1481 & 616,4 & 84,73 \\
\hline & 2007 & 153,6 & 839,4 & 1469 & 325,7 & 103,8 \\
\hline \multirow{4}{*}{ Coeficiente de Variação } & 2010 & 126,00 & 98,21 & 168,92 & 130,85 & 106,18 \\
\hline & 2009 & 368,24 & 429,67 & 149,86 & 237,74 & 243,16 \\
\hline & 2008 & 576,57 & 369,29 & 126,80 & 193,29 & 205,86 \\
\hline & 2007 & 15,96 & 15,24 & 6,08 & 7,71 & 10,13 \\
\hline
\end{tabular}

Fonte: dados da pesquisa. Notas: I é lucro líquido legal; II é riqueza criada; III é número de empregados; IV é riqueza criada por empregado; e V é salários e encargos.

Buscando atingir o objetivo proposto, ao realizar-se a correlação canônica são calculadas as combinações lineares entre as variáveis dos grupos de análise. Para o presente estudo sempre foram obtidas duas combinações, visto que este é o número mínimo de variáveis contidas em um grupo de análise. Sendo assim, estas combinações são apresentadas nas tabelas, porém apenas a combinação de cada ano é significativa e apenas estas foram analisadas.

O teste Qui-quadrado busca verificar a significância das combinações lineares, fazendo uma comparação do Qui-quadrado tabelado e o apresentado na tabela de correlação. Para os valores de grau de liberdade apresentados na análise, bem como para os setores, foram identificados dois valores, sendo 6 para a primeira combinação linear e 2 para a segunda. Esses valores foram obtidos a partir do produto entre o número de variáveis dos grupos analisados. Para o segundo valor, retira-se uma variável de cada grupo e encontra-se o respectivo grau de liberdade.

Já os valores do autovalor e do Wilks lambda demonstrados nas tabelas subsequentes, determinam a matriz de covariância de cada variável analisada, sendo esta responsável por determinar a correlação entre ambas. Os resultados obtidos com a correlação canônica do setor de atacado são apresentados na Tabela 3.

Tabela 3 - Correlações canônicas do setor de atacado.

\begin{tabular}{cccccccc}
\hline \multirow{2}{*}{ Ano } & $\begin{array}{c}\text { Combinação } \\
\text { Linear }\end{array}$ & Autovalor & $\begin{array}{c}\text { Correlação } \\
\text { Canônica }\end{array}$ & Wilks Lambda & Qui-Quadrado & $\begin{array}{c}\text { Grau de } \\
\text { Liberdade }\end{array}$ & $\boldsymbol{P}$-Valor \\
\hline \multirow{2}{*}{2010} & 1 & 0.769296 & 0.877095 & 0.220998 & 33.2113 & 6 & $0.0000^{*}$ \\
& 2 & 0.0420699 & 0.205109 & 0.95793 & 0.94557 & 2 & 0.6233 \\
\hline \multirow{2}{*}{2009} & 1 & 0.979073 & 0.989481 & 0.0207392 & 147.278 & 6 & $0.0000^{*}$ \\
& 2 & 0.00896018 & 0.0946582 & 0.99104 & 0.342022 & 2 & 0.8428 \\
\hline \multirow{2}{*}{2008} & 1 & 0.988463 & 0.994215 & 0.0105165 & 127.535 & 6 & $0.0000^{*}$ \\
& 2 & 0.0884829 & 0.297461 & 0.911517 & 2.59406 & 2 & 0.2733 \\
\hline \multirow{2}{*}{2007} & 1 & 0.968945 & 0.98435 & 0.0252502 & 40.4681 & 6 & $0.0000^{*}$ \\
& 2 & 0.18692 & 0.432343 & 0.81308 & 2.27619 & 2 & 0.3204 \\
\hline
\end{tabular}

Fonte: dados da pesquisa. Notas: * Significância ao nível de 0,05.

Diante os dados apresentados na Tabela 3, no setor de atacado, referentes ao ano de 2010 a correlação existente é de $87,70 \%$ para a combinação linear 1 , que pode ser considerada uma corre- 
lação elevada, sendo que, para esse setor, os indicadores do grupo B apresentam relação com os indicadores do grupo A. Observa-se que no ano de 2009 há uma correlação que pode ser considerada forte, sendo de $98,94 \%$. Os $P$-valores são significativos para as primeiras combinações lineares ao nível de 0,05 .

Já no ano de 2008 a correlação canônica apresenta um percentual de 99,42\%, sugerindo uma elevada correlação. Comparando esse percentual com os anos de 2010 e 2009, percebe-se que os dados analisados nos grupos A e B apresentaram maior influência entre si. E em 2007, a correlação infere em 98,43\%, também podendo ser considerada elevada correlação canônica entre os dados analisados. Com o alto valor da correlação entre os grupos A e B, constata-se que existe relação entre a distribuição do valor adicionado aos agentes colaboradores na formação da riqueza e a lucratividade das empresas desse setor.

Nesse sentido, percebeu-se uma redução, ao longo do período analisado, da intensidade da correlação entre as variáveis, o que foi proporcional à heterogeneidade da lucratividade das empresas do referido setor, sugerindo que a heterogeneidade combinada à diminuição da lucratividade das empresas contribuiu para diminuir a relação entre a distribuição do valor adicionado aos colaboradores e a lucratividade.

A Tabela 4 demonstra a estatística descritiva do setor de bens de consumo, visando identificar a diferença entre os dados analisados no decorrer dos anos de 2007 a 2010, considerando os cinco indicadores avaliados.

Tabela 4 - Estatísticas descritivas do setor de bens de consumo.

\begin{tabular}{ccccccc}
\hline \multirow{2}{*}{ Estatística } & \multicolumn{7}{c}{ Setor } & \multicolumn{5}{c}{ Bens de consumo } \\
\cline { 2 - 7 } & Indicador & I & II & III & IV & V \\
\hline \multirow{3}{*}{ Média } & 2010 & 188,1 & 658,6 & 6348 & 146,4 & 183,1 \\
& 2009 & 168,9 & 576,2 & 5491 & 150,1 & 91,9 \\
& 2008 & 42,98 & 576,4 & 4355 & 135,9 & 80,71 \\
& 2007 & 184 & 1109 & 7455 & 173,4 & 166,8 \\
\hline \multirow{3}{*}{ Mediana } & 2010 & 14 & 154,7 & 1686 & 71,1 & 29,8 \\
& 2009 & 22,4 & 107,2 & 1556 & 88,3 & 26,7 \\
& 2008 & 11,5 & 124,6 & 1554 & 80,7 & 25,6 \\
Desvio padrão & 2007 & 44,75 & 387,4 & 3749 & 94,8 & 121,8 \\
\hline \multirow{3}{*}{ Coeficiente de Variação } & 2010 & 676,4 & 1491 & 13220 & 209,9 & 540,2 \\
& 2009 & 579,4 & 1475 & 16992 & 238,5 & 163,8 \\
& 2008 & 439,5 & 1442 & 9773 & 155,5 & 163 \\
& 2007 & 453,2 & 2190 & 11189 & 209 & 188,7 \\
\hline
\end{tabular}

Fonte: dados da pesquisa. Notas: I é lucro líquido legal; II é riqueza criada; III é número de empregados; IV é riqueza criada por empregado; e V é salários e encargos.

Assim como apresentado na Tabela 2, os dados da Tabela 4 demonstram certa disparidade entre a média e a mediana no decorrer dos quatro anos analisados, bem como para os cinco indicadores estudados. Destaque para o indicador I, no ano de 2008, o qual obteve uma heterogeneidade de mais de mil por cento. Em 2010, pode se perceber que o indicador I, lucro líquido legal médio, foi de 188,1, sendo que a mediana foi de 14 e o desvio padrão de 676,4. Já a Tabela 5 apresenta a correlação canônica do setor de bens de consumo para os anos analisados.

A partir das informações dispostas na Tabela 5, observa-se que os dados das combinações lineares 1 demonstraram significância, haja vista ter apresentado um coeficiente $P$-valor ao nível de significância de 0,05. A correlação canônica para o ano de 2010 foi de 72,22\%, o que representa 
uma alta correlação canônica, e para o ano de 2008, uma correlação de $94,42 \%$, demonstrando correlação moderada entre os indicadores do grupo A com os do grupo B.

Tabela 5 - Correlações canônicas do setor de bens de consumo.

\begin{tabular}{cccccccc}
\hline \multirow{2}{*}{ Ano } & $\begin{array}{c}\text { Combinação } \\
\text { Linear }\end{array}$ & Autovalor & $\begin{array}{c}\text { Correlação } \\
\text { Canônica }\end{array}$ & Wilks Lambda & Qui-Quadrado & $\begin{array}{c}\text { Grau de } \\
\text { Liberdade }\end{array}$ & $\boldsymbol{P}$-Valor \\
\hline \multirow{2}{*}{2010} & 1 & 0.521612 & 0.722227 & 0.427612 & 36.5302 & 6 & $0.0000^{*}$ \\
& 2 & 0.10614 & 0.325792 & 0.89386 & 4.82488 & 2 & 0.0896 \\
\hline \multirow{2}{*}{2009} & 1 & 0.844874 & 0.91917 & 0.139695 & 80.7002 & 6 & $0.0000^{*}$ \\
& 2 & 0.0994786 & 0.315402 & 0.900521 & 4.29603 & 2 & 0.1167 \\
\hline \multirow{2}{*}{2008} & 1 & 0.89167 & 0.944283 & 0.0708612 & 97.9402 & 6 & $0.0000^{*}$ \\
& 2 & 0.345879 & 0.588115 & 0.654121 & 15.7051 & 2 & 0.0004 \\
\hline \multirow{2}{*}{2007} & 1 & 0.815013 & 0.902781 & 0.139929 & 35.3991 & 6 & $0.0000^{*}$ \\
& 2 & 0.24357 & 0.493528 & 0.75643 & 5.02461 & 2 & 0.0811 \\
\hline
\end{tabular}

Fonte: dados da pesquisa. Nota: * Significância ao nível de 0,05 .

Ainda na Tabela 5, verifica-se elevada correlação diante dos dados analisados nos anos de 2009 e 2008, em que há uma correlação existente de $91,91 \%$ e 94,42\%, respectivamente, indicando correlação entre os indicadores do grupo A e os indicadores do grupo B. Outra constatação decorre da elevada correlação auferida em 2007, com 90,27\% de correlação entre os indicadores utilizados.

Os resultados evidenciam que, assim como o setor de atacado, o setor de bens de consumo também apresenta associação entre a distribuição do valor adicionado aos agentes colaboradores e a lucratividade das empresas. Destaque se dá para ano de 2008, tanto para o setor de atacado como bens de consumo, pois ambos apresentaram maior correlação, se comparados aos demais anos analisados, sendo de $99,42 \%$ para o setor de atacado e $94,48 \%$ para bens de consumo no ano de 2008. Esse destaque pode ter relação com o fato de o setor de bens de consumo ter apresentado maior quantidade de funcionários para esse ano, se comparado com o setor de atacado.

Para o setor de produção agropecuária, também são apresentados a estatística descritiva e a correlação canônica dos indicadores utilizados nos respectivos anos de análise. A Tabela 6 demonstra a média, a mediana e o desvio padrão dos respectivos indicadores analisados no período de 2007 a 2010.

Tabela 6 - Estatísticas descritivas do setor de produção agropecuária.

\begin{tabular}{|c|c|c|c|c|c|c|}
\hline \multirow{2}{*}{ Estatística } & \multirow{2}{*}{$\begin{array}{c}\text { Setor } \\
\text { Indicador }\end{array}$} & \multicolumn{5}{|c|}{ Produção agropecuária } \\
\hline & & $\mathbf{I}$ & II & III & IV & $\mathbf{V}$ \\
\hline \multirow{4}{*}{ Média } & 2010 & 13,91 & 65,91 & 1796 & 48,49 & 25,37 \\
\hline & 2009 & 23,35 & 65,99 & 1843 & 46,78 & 26,37 \\
\hline & 2008 & 12,41 & 77,76 & 1695 & 65,6 & 24,11 \\
\hline & 2007 & 33,71 & 150,2 & 3510 & 66,58 & 45,23 \\
\hline \multirow{4}{*}{ Mediana } & 2010 & 6,9 & 31,4 & 914 & 33,3 & 15,25 \\
\hline & 2009 & 7,25 & 37 & 1002 & 33,25 & 15,85 \\
\hline & 2008 & 6,8 & 36,9 & 905 & 39,5 & 12,2 \\
\hline & 2007 & 21,4 & 114,6 & 2784 & 49,2 & 27,95 \\
\hline \multirow{4}{*}{ Desvio padrão } & 2010 & 29,88 & 93,91 & 2273 & 37,25 & 31,9 \\
\hline & 2009 & 71,89 & 95,82 & 2271 & 38,42 & 31,86 \\
\hline & 2008 & 32,39 & 103,8 & 1976 & 81,87 & 28,94 \\
\hline & 2007 & 45,9 & 138,3 & 3216 & 50,11 & 42,91 \\
\hline \multirow{4}{*}{ Coeficiente de Variação } & 2010 & 214,81 & 142,48 & 126,56 & 76,82 & 125,74 \\
\hline & 2009 & 307,88 & 145,20 & 123,22 & 82,13 & 120,82 \\
\hline & 2008 & 261,00 & 133,49 & 116,58 & 124,80 & 120,03 \\
\hline & 2007 & 136,16 & 92,08 & 91,62 & 75,26 & 94,87 \\
\hline
\end{tabular}

Fonte: dados da pesquisa. Notas: I é lucro líquido legal; II é riqueza criada; III é número de empregados; IV é riqueza criada por empregado; e V é salários e encargos. 
A Tabela 6 aponta alta discrepância entre os valores das variáveis, quanto ao setor de produção agropecuária, por meio da percepção de altos coeficientes de variação. Além disso, comparando a média e a mediana das variáveis estudadas, como o lucro líquido legal, a riqueza criada, o número de empregados, a riqueza criada por empregado e os salários e encargos, constata-se que há distância entre ambas no decorrer dos quatro anos analisados, sendo que o desvio padrão dos respectivos dados apresentou resultado elevado. Adicionalmente, percebe-se que a média dos indicadores de desempenho do referido setor sofre diminuição ao longo dos anos analisados. O setor de produção agropecuária também apresentou variância explicativa no cálculo das correlações canônicas, conforme apresentado na Tabela 7.

Tabela 7 - Correlações canônicas do setor de produção agropecuária.

\begin{tabular}{cccccccc}
\hline \multirow{2}{*}{ Ano } & $\begin{array}{c}\text { Combinação } \\
\text { Linear }\end{array}$ & Autovalor & $\begin{array}{c}\text { Correlação } \\
\text { Canônica }\end{array}$ & Wilks Lambda & Qui-Quadrado & $\begin{array}{c}\text { Grau de } \\
\text { Liberdade }\end{array}$ & $\boldsymbol{P}$-Valor \\
\hline \multirow{2}{*}{2010} & 1 & 0.932378 & 0.965597 & 0.0476823 & 124.771 & 6 & $0.0000^{*}$ \\
& 2 & 0.294869 & 0.543019 & 0.705131 & 14.3242 & 2 & 0.0008 \\
\hline \multirow{2}{*}{2009} & 1 & 0.949812 & 0.974583 & 0.0418989 & 120.555 & 6 & $0.0000^{*}$ \\
& 2 & 0.165162 & 0.406401 & 0.834838 & 6.85968 & 2 & 0.0324 \\
\hline \multirow{2}{*}{2008} & 1 & 0.884564 & 0.940513 & 0.0777443 & 114.945 & 6 & $0.0000^{*}$ \\
& 2 & 0.326516 & 0.571415 & 0.673484 & 17.7881 & 2 & 0.0001 \\
\hline \multirow{2}{*}{2007} & 1 & 0.932307 & 0.96556 & 0.0561909 & 23.032 & 6 & 0.0008 \\
& 2 & 0.169921 & 0.412214 & 0.830079 & 1.48987 & 2 & 0.4748 \\
\hline
\end{tabular}

Fonte: dados da pesquisa. Nota: * Significância ao nível de 0,05 .

Para os dados apresentados na Tabela 7, constata-se que as variáveis analisadas foram significativas ao nível de 0,05 para as combinações lineares 1 . Contudo, em 2007, o $P$-valor não apresentou significância perante os demais, visto o nível estipulado $(0,05)$. Em 2010, a correlação canônica para a combinação linear 1 foi de 96,55\%, podendo ser considerada uma forte correlação. Constata-se, portanto, que há uma influência substancial dos indicadores do grupo A perante os indicadores do grupo B. Já em 2009 a correlação canônica para a combinação 1 foi de 97,45\%, o que demonstra que nesse ano os dados foram melhor distribuídos, se comparados com os anos anteriores e posteriores, sendo que a correlação canônica para 2008 e 2007 foi de 94,05\% e 96,55\%, respectivamente. Destaca-se, portanto que com altos valores de correlação entre os grupos A e B, há influência na distribuição do valor adicionado aos agentes colaboradores e o lucro das empresas para o setor de produção agropecuária nos anos de 2007, 2008, 2009 e 2010.

Por meio das variáveis analisadas no decorrer dos cinco anos, foram calculados a média, a mediana e o desvio padrão do setor de química e petroquímica, sendo os dados apresentados na Tabela 8.

A partir das informações dispostas na Tabela 8, observa-se que, dos indicadores analisados neste setor, o que obteve maior discrepância nos valores foi o indicador I, com coeficiente de variação bastante elevado. Os demais indicadores apresentaram, no decorrer do período analisado, discrepância entre os valores, tanto para média como para a mediana e o desvio padrão. Ainda, com relação ao setor de química e petroquímica, são expostos na Tabela 9, os dados referentes às correlações canônicas calculadas para as combinações lineares 1 e 2. 
Tabela 8 - Estatísticas descritivas do setor de química e petroquímica.

\begin{tabular}{|c|c|c|c|c|c|c|}
\hline \multirow{2}{*}{ Estatística } & \multirow{2}{*}{$\begin{array}{c}\text { Setor } \\
\text { Indicador }\end{array}$} & \multicolumn{5}{|c|}{ Química e petroquímica } \\
\hline & & $\mathbf{I}$ & II & III & IV & $\mathbf{V}$ \\
\hline \multirow{4}{*}{ Média } & 2010 & 66,28 & 285,8 & 1005 & 344,6 & 55,28 \\
\hline & 2009 & 54,43 & 197,6 & 798,8 & 285,6 & 40,68 \\
\hline & 2008 & $-90,39$ & 248,5 & 1316 & 290,4 & 78,26 \\
\hline & 2007 & 103,9 & 389,9 & 1246 & 494,4 & 90,15 \\
\hline \multirow{4}{*}{ Mediana } & 2010 & 30,5 & 129,1 & 410 & 199,7 & 22,6 \\
\hline & 2009 & 24,8 & 49,1 & 382 & 206,6 & 25 \\
\hline & 2008 & 40,65 & 116,1 & 835,5 & 184,1 & 42,15 \\
\hline & 2007 & 90 & 233,6 & 811 & 308,7 & 44,4 \\
\hline \multirow{4}{*}{ Desvio padrão } & 2010 & 212,9 & 571,4 & 1203 & 518,8 & 86,42 \\
\hline & 2009 & 149,5 & 519,3 & 1046 & 548,4 & 71,67 \\
\hline & 2008 & 421,9 & 322,3 & 1288 & 343,6 & 96,42 \\
\hline & 2007 & 91,65 & 557,5 & 1072 & 726,1 & 90,39 \\
\hline \multirow{4}{*}{ Coeficiente de Variação } & 2010 & 321,21 & 199,93 & 119,70 & 150,55 & 156,33 \\
\hline & 2009 & 274,66 & 262,80 & 130,95 & 192,02 & 176,18 \\
\hline & 2008 & $-466,76$ & 129,70 & 97,87 & 118,32 & 123,20 \\
\hline & 2007 & 88,21 & 142,99 & 86,04 & 146,86 & 100,27 \\
\hline
\end{tabular}

Fonte: dados da pesquisa. Notas: I é lucro líquido legal; II é riqueza criada; III é número de empregados; IV é riqueza criada por empregado; e V é salários e encargos.

Considera-se que as combinações lineares 1 calculadas foram significantes ao nível de 0,05 para os anos de 2010, 2009, 2008 e 2007, sendo que em 2010 a combinação linear 2 também apresentou significância. A correlação entre as variáveis analisadas e explicadas na combinação linear 1 demonstra uma forte correlação em 2010, sendo esta de 96,75\%.

Destaca-se que a combinação 2, para o ano de 2010, por apresentar significância, demonstrou uma correlação canônica de $75,67 \%$, sendo essa um percentual próximo da combinação linear 1 , se comparado com os demais anos analisados.

Na sequência, verifica-se forte correlação canônica na combinação linear 1 do ano de 2008, sendo esta de 93,12\%, seguido de 2009 e 2008 com correlações de 94,64\% e 93,12\%, respectivamente. Os resultados da correlação canônica para o setor de química e petroquímica sugerem que a distribuição do valor adicionado aos agentes colaboradores e o lucro das empresas apresentaram influência, visto a forte relação dos indicadores do grupo A perante os indicadores do grupo B.

Tabela 9 - Correlações canônicas do setor de química e petroquímica.

\begin{tabular}{cccccccc}
\hline \multirow{2}{*}{ Ano } & $\begin{array}{c}\text { Combinação } \\
\text { Linear }\end{array}$ & Autovalor & $\begin{array}{c}\text { Correlação } \\
\text { Canônica }\end{array}$ & Wilks Lambda & Qui-Quadrado & $\begin{array}{c}\text { Grau de } \\
\text { Liberdade }\end{array}$ & P-Valor \\
\hline \multirow{2}{*}{2010} & 1 & 0.936116 & 0.967531 & 0.0273015 & 90.0203 & 6 & $0.0000^{*}$ \\
& 2 & 0.57264 & 0.75673 & 0.42736 & 21.2532 & 2 & $0.0000^{*}$ \\
\hline \multirow{2}{*}{2009} & 1 & 0.895794 & 0.946464 & 0.0919599 & 83.5241 & 6 & $0.0000^{*}$ \\
& 2 & 0.117514 & 0.342803 & 0.882486 & 4.37544 & 2 & 0.1122 \\
\hline \multirow{2}{*}{2008} & 1 & 0.867243 & 0.931259 & 0.121906 & 37.8812 & 6 & $0.0000^{*}$ \\
& 2 & 0.081739 & 0.2859 & 0.918261 & 1.53492 & 2 & 0.4642 \\
\hline \multirow{2}{*}{2007} & 1 & 0.94482 & 0.972019 & 0.0434181 & 59.6007 & 6 & $0.0000^{*}$ \\
& 2 & 0.213155 & 0.461687 & 0.786845 & 4.55475 & 2 & 0.1026 \\
\hline
\end{tabular}

Fonte: dados da pesquisa. Nota: * Significância ao nível de 0,05.

No que se refere à estatística descritiva referente às empresas que compõem o setor de varejo, é possível observar a discrepância entre os valores médios e medianos, conforme exposto na Tabela 10. 
Tabela 10 - Estatísticas descritivas do setor de varejo.

\begin{tabular}{|c|c|c|c|c|c|c|}
\hline \multirow{2}{*}{ Estatísticas } & \multirow{2}{*}{$\begin{array}{c}\text { Setor } \\
\text { Indicador }\end{array}$} & \multicolumn{5}{|c|}{ Varejo } \\
\hline & & I & II & III & IV & $\mathbf{V}$ \\
\hline \multirow{4}{*}{ Média } & 2010 & 31,93 & 247,5 & 6424 & 57,64 & 85,29 \\
\hline & 2009 & 25,57 & 230,1 & 5167 & 52,97 & 80,14 \\
\hline & 2008 & 19,45 & 187 & 5526 & 52,75 & 72,32 \\
\hline & 2007 & 30,26 & 361,4 & 9454 & 41,8 & 154 \\
\hline \multirow{4}{*}{ Mediana } & 2010 & 9,5 & 131,9 & 4100 & 40,2 & 58,2 \\
\hline & 2009 & 7,1 & 106 & 2710 & 44,5 & 43,05 \\
\hline & 2008 & 8,05 & 70,9 & 2439 & 43 & 38,05 \\
\hline & 2007 & 14,5 & 237,5 & 6283 & 35,8 & 77,4 \\
\hline \multirow{4}{*}{ Desvio padrão } & 2010 & 70,99 & 345,5 & 9435 & 58,63 & 93,71 \\
\hline & 2009 & 58,01 & 400,2 & 8412 & 34,79 & 123,7 \\
\hline & 2008 & 37,95 & 309,2 & 11316 & 41,52 & 127,1 \\
\hline & 2007 & 42,65 & 373,2 & 11020 & 18,77 & 246,6 \\
\hline \multirow{4}{*}{$\begin{array}{l}\text { Coeficiente de } \\
\text { Variação }\end{array}$} & 2010 & 222,33 & 139,60 & 146,87 & 101,72 & 109,87 \\
\hline & 2009 & 226,87 & 173,92 & 162,80 & 65,68 & 154,35 \\
\hline & 2008 & 195,12 & 165,35 & 204,78 & 78,71 & 175,75 \\
\hline & 2007 & 140,95 & 103,27 & 116,56 & 44,90 & 160,13 \\
\hline
\end{tabular}

Fonte: dados da pesquisa. Notas: I é lucro líquido legal; II é riqueza criada; III é número de empregados; IV é riqueza criada por empregado; e V é salários e encargos.

Assim, como já observado nos setores anteriormente analisados, os valores dos indicadores, no caso desse setor, foram consideravelmente discrepantes, destacando-se, novamente em 2010, o indicador do lucro líquido legal (I), que obteve valor médio de 31,93 e mediana de 9,5, representando assim o indicador mais heterogêneo do período. É possível perceber ainda que a média dos indicadores, em sua maioria, comporta-se de forma decrescente, sugerindo que os mesmos sofreram decréscimo no decorrer dos anos investigados.

Considerando que a correlação canônica "facilita o estudo de inter-relações entre conjuntos de múltiplas variáveis dependentes e múltiplas variáveis independentes" (HAIR JR. et. al., 2005, p. 362), a Tabela 11, demonstra tal correlação referente as empresas pertencentes ao setor de varejo, considerando as cinco variáveis analisadas.

Tabela 11 - Correlações canônicas do setor de varejo.

\begin{tabular}{cccccccc}
\hline \multirow{2}{*}{ Ano } & $\begin{array}{c}\text { Combinação } \\
\text { Linear }\end{array}$ & Autovalor & $\begin{array}{c}\text { Correlação } \\
\text { Canônica }\end{array}$ & Wilks Lambda & Qui-Quadrado & $\begin{array}{c}\text { Grau de } \\
\text { Liberdade }\end{array}$ & $P$-Valor \\
\hline \multirow{2}{*}{2010} & 1 & 0.934596 & 0.966745 & 0.0337304 & 145.742 & 6 & $0.0000^{*}$ \\
& 2 & 0.484274 & 0.695898 & 0.515726 & 28.4737 & 2 & $0.0000^{*}$ \\
\hline \multirow{2}{*}{2009} & 1 & 0.953617 & 0.976533 & 0.0455919 & 129.697 & 6 & $0.0000^{*}$ \\
& 2 & 0.0170513 & 0.130581 & 0.982949 & 0.72233 & 2 & 0.6969 \\
\hline \multirow{2}{*}{2008} & 1 & 0.911209 & 0.954573 & 0.0813558 & 90.3212 & 6 & $0.0000^{*}$ \\
& 2 & 0.0837342 & 0.289369 & 0.916266 & 3.14816 & 2 & 0.2072 \\
\hline \multirow{2}{*}{2007} & 1 & 0.985004 & 0.992474 & 0.0141343 & 59.6281 & 6 & $0.0000^{*}$ \\
& 2 & 0.0574665 & 0.239722 & 0.942533 & 0.828574 & 2 & 0.6608 \\
\hline
\end{tabular}

Fonte: dados da pesquisa. Nota: * Significância ao nível de 0,05

Dos dados apresentados na Tabela 11, percebe-se que há significância em todos os indicadores analisados e inseridos na combinação linear 1. Em 2010, o $P$-valor da combinação linear 2 também demonstrou significância. Observa-se uma forte correlação canônica para os quatro anos analisados, considerando a combinação linear 1, sendo que em 2007 a correlação foi de 99,24\%, seguido de $97,65 \%$ para $2009,96,67 \%$ para o ano de 2010 e 95,45 para 2008 . Conforme observado, este setor também apresentou influência entre os grupos A e B, sugerindo correlação entre a distribuição do valor adicionado aos agentes colaboradores e o lucro das empresas. 
A Tabela 12 apresenta a estatística descritiva das empresas pertencentes ao setor da indústria da construção, com descrição da diferença entre média, mediana e desvio padrão, identificando a distância ente os dados analisados.

Tabela 12 - Estatísticas descritivas do setor de indústria da construção.

\begin{tabular}{ccccccc}
\hline \multirow{2}{*}{ Estatística } & \multicolumn{7}{c}{ Setor } & \multicolumn{5}{c}{ Indústria de Construção } \\
\cline { 2 - 7 } & Indicador & I & II & III & IV & V \\
\hline \multirow{3}{*}{ Média } & 2010 & 124,4 & 423,7 & 6928 & 112,5 & 169 \\
& 2009 & 78,15 & 303,4 & 6401 & 102,1 & 163,6 \\
& 2008 & 56,67 & 268,8 & 6066 & 95,05 & 142,2 \\
& 2007 & 74,63 & 327 & 6350 & 98,05 & 151,8 \\
\hline \multirow{3}{*}{ Mediana } & 2010 & 42,55 & 242,1 & 2428 & 75,8 & 98 \\
& 2009 & 40,2 & 190,1 & 2391 & 75 & 68,4 \\
& 2008 & 43,4 & 158,1 & 2299 & 68,85 & 59 \\
Desvio padrão & 2007 & 75,05 & 266,1 & 3844 & 60,8 & 103,8 \\
& 2010 & 249,8 & 464,8 & 14352 & 98,25 & 232,8 \\
& 2009 & 132,9 & 322,9 & 12543 & 83,57 & 309,4 \\
& 2008 & 78,36 & 308,7 & 13216 & 84,22 & 298,4 \\
& 2007 & 70,17 & 256 & 6066 & 77,71 & 144,3 \\
\hline \multirow{5}{*}{ Coeficiente de Variação } & 2010 & 200,80 & 109,70 & 207,16 & 87,33 & 137,75 \\
& 2009 & 170,06 & 106,43 & 195,95 & 81,85 & 189,12 \\
& 2008 & 138,27 & 114,84 & 217,87 & 88,61 & 209,85 \\
\hline
\end{tabular}

Fonte: dados da pesquisa. Notas: I é lucro líquido legal; II é riqueza criada; III é número de empregados; IV é riqueza criada por empregado; e V é salários e encargos.

Analisando os dados apresentados na Tabela 12, para o ano de 2010, os indicadores do setor de indústria da construção apresentaram, em média, uma riqueza criada pelo empregado (indicador V) de 169, com mediana de 98 . Nesse caso, quanto maior for a distância entre a média e a mediana, maior será a disparidade entre os dados, apresentando um desvio padrão de 232,8 para o ano de 2010, sendo que em 2007 esse indicador apresentou menor valor entre os demais analisados. Isso demonstra, tanto para esse indicador como para os demais, que os dados não estão próximos.

Na Tabela 13, por sua vez, está demonstrada a correlação canônica calculada para as combinações lineares identificadas entre o setor de indústria da construção e anos analisados.

Tabela 13 - Correlações canônicas do setor de indústria da construção.

\begin{tabular}{cccccccc}
\hline \multirow{2}{*}{ Ano } & $\begin{array}{c}\text { Combinação } \\
\text { linear }\end{array}$ & Autovalor & $\begin{array}{c}\text { Correlação } \\
\text { Canônica }\end{array}$ & Wilks Lambda Qui-Quadrado & $\begin{array}{c}\text { Grau de Li- } \\
\text { berdade }\end{array}$ & P-Value \\
\hline \multirow{2}{*}{2010} & 1 & 0.92966 & 0.964189 & 0.0551134 & 133.325 & 6 & $0.0000^{*}$ \\
& 2 & 0.216469 & 0.465262 & 0.783531 & 11.2215 & 2 & 0.0037 \\
\hline \multirow{2}{*}{2009} & 1 & 0.580263 & 0.76175 & 0.399255 & 40.3989 & 6 & $0.0000^{*}$ \\
& 2 & 0.0487974 & 0.220901 & 0.951203 & 2.20124 & 2 & 0.3327 \\
\hline \multirow{2}{*}{2008} & 1 & 0.724862 & 0.851388 & 0.274536 & 54.2922 & 6 & $0.0000^{*}$ \\
& 2 & 0.00218691 & 0.0467644 & 0.997813 & 0.0919506 & 2 & 0.9551 \\
\hline \multirow{2}{*}{2007} & 1 & 0.896457 & 0.946814 & 0.101575 & 18.2957 & 6 & $0.0055^{*}$ \\
& 2 & 0.0190111 & 0.137881 & 0.980989 & 0.153553 & 2 & 0.9261 \\
\hline
\end{tabular}

Fonte: dados da pesquisa. Nota: * Significância ao nível de 0,05.

Conforme exposto na Tabela 13, observa-se que as correlações foram significantes ao nível de 0,05 para as combinações lineares 1 . Dentre as significâncias, o ano de 2007 apresentou uma pequena oscilação diante o $P$-valor de 0,0055 , porém, não deixa de ser significante. 
Para esse setor de indústria da construção, percebe-se que as correlações canônicas dos anos observados apresentaram diferença de valores, se comparados com os demais setores. Isto se dá visto ter apresentado uma forte correlação no ano de 2010 e 2007, sendo respectivamente de 96,41 e 94,68\%, e uma correlação para os anos de 2009 de 76,17\% e em 2008 de 85,13\%, considerando a primeira combinação.

Observa-se que os dados de 2007 e 2010 sugerem forte influência entre a distribuição do valor adicionado aos agentes colaboradores e a lucratividade das empresas do setor de indústria da construção, sendo que para 2008 e 2009 a correlação dessa distribuição foi menor. Essa correlação em 2008 e 2009 pode estar relacionada com os salários e encargos dos funcionários e o lucro líquido legal das empresas, visto que ambos os indicadores apresentaram maiores coeficientes na equação da correlação, e consequentemente maior influência sobre os demais.

Para o setor de energia, a estatística descritiva e a correlação canônica também foram calculadas para se atingir o objetivo proposto por esse estudo (Tabela 14).

Tabela 14 - Estatísticas descritivas do setor de energia.

\begin{tabular}{|c|c|c|c|c|c|c|}
\hline \multirow{2}{*}{ Estatística } & \multirow{2}{*}{$\begin{array}{c}\text { Setor } \\
\text { Indicador }\end{array}$} & \multicolumn{5}{|c|}{ Energia } \\
\hline & & I & II & III & IV & $\mathbf{V}$ \\
\hline \multirow{4}{*}{ Média } & 2010 & 419 & 1609 & 2916 & 627,9 & 177,1 \\
\hline & 2009 & 347,6 & 1405 & 2789 & 1067 & 155,5 \\
\hline & 2008 & 402,4 & 1675 & 2889 & 1052 & 161,6 \\
\hline & 2007 & 551,9 & 2887 & 4065 & 665,6 & 248 \\
\hline \multirow{4}{*}{ Mediana } & 2010 & 64,9 & 245,5 & 1308 & 386,2 & 40,6 \\
\hline & 2009 & 71,8 & 274,5 & 1294 & 418,7 & 40,8 \\
\hline & 2008 & 50,5 & 309,3 & 1278 & 473 & 40,9 \\
\hline & 2007 & 132,9 & 802,7 & 1626 & 571,9 & 93,05 \\
\hline \multirow{4}{*}{ Desvio padrão } & 2010 & 2394 & 8686 & 6982 & 864,4 & 793,5 \\
\hline & 2009 & 1998 & 7405 & 6441 & 3494 & 696,8 \\
\hline & 2008 & 2768 & 8965 & 7081 & 2533 & 705 \\
\hline & 2007 & 2300 & 12491 & 7868 & 700,8 & 854,2 \\
\hline \multirow{4}{*}{ Coeficiente de Variação } & 2010 & 571,36 & 539,84 & 239,44 & 137,67 & 448,05 \\
\hline & 2009 & 574,80 & 527,05 & 230,94 & 327,46 & 448,10 \\
\hline & 2008 & 687,87 & 535,22 & 245,10 & 240,78 & 436,26 \\
\hline & 2007 & 416,74 & 432,66 & 193,55 & 105,29 & 344,44 \\
\hline
\end{tabular}

Fonte: dados da pesquisa. Notas: I é lucro líquido legal; II é riqueza criada; III é número de empregados; IV é riqueza criada por empregado; e V é salários e encargos.

A partir das informações dispostas na Tabela 14, observa-se que, assim como os demais setores, há uma discrepância grande entre a média e a mediana dos indicadores analisados, e consequentemente, os desvios padrões desses dados apresentam um valor elevado. Sob a perspectiva geral da distribuição, confirma-se tal heterogeneidade a partir dos altos valores do coeficiente de variação dos indicadores, especialmente do indicador I, cuja discrepância se destacou na maioria dos setores, o que sugere que o lucro líquido legal se apresentou de forma bastante diferente nas empresas dos setores considerados no estudo. Vale ressaltar que tal indicador consiste no resultado nominal do exercício que não considera a inflação. Assim como em setores anteriormente analisados, percebe-se que os indicadores sofreram um declínio ao longo dos anos, verificado por meio dos decrescentes valores médios dos mesmos no período de análise.

Consta na Tabela 15 a correlação canônica calculada para o setor de energia. Para o setor de energia, é possível observar que há significância ao nível de 0,05 para todas as combinações lineares 1, nos anos analisados. Consequentemente, todas as combinações 1 apresentaram forte correlação para os respectivos anos, demonstrando aproximadamente $99 \%$ de correlação canônica entre os indicadores. 


\begin{tabular}{cccccccc}
\multicolumn{7}{c}{ Tno } & \multicolumn{7}{c}{$\begin{array}{c}\text { Tabela 15 - Correlações canônicas do setor de energia. } \\
\text { Linear }\end{array}$} & \begin{tabular}{c} 
Autovalor \\
\multirow{2}{*}{2010}
\end{tabular} & $\begin{array}{c}\text { Correlação } \\
\text { Canônica }\end{array}$ & Wilks Lambda & Qui-Quadrado & $\begin{array}{c}\text { Grau de } \\
\text { Liberdade }\end{array}$ & $\boldsymbol{P}$-Valor \\
& 1 & 0.991087 & 0.995533 & 0.00887619 & 344.88 & 6 & $0.0000^{*}$ \\
\multirow{2}{*}{2009} & 1 & 0.00418229 & 0.0646706 & 0.995818 & 0.305947 & 2 & 0.8582 \\
\hline \multirow{2}{*}{2008} & 2 & 0.986327 & 0.99314 & 0.012411 & 364.301 & 6 & $0.0000^{*}$ \\
& 1 & 0.9922839 & 0.303783 & 0.907716 & 8.03636 & 2 & 0.0180 \\
\hline \multirow{2}{*}{2007} & 2 & 0.0196308 & 0.14011 & 0.980369 & 1.4473 & 2 & $0.0000^{*}$ \\
& 1 & 0.991619 & 0.995801 & 0.0083386 & 210.622 & 6 & 0.4850 \\
\hline
\end{tabular}

Fonte: dados da pesquisa. Nota: * Significância ao nível de 0,05.

Essa forte correlação identificada nas combinações 1 pode ter parte da explicação encontrada pelos autovalores e o lambda, visto que são esses que determinam a matriz de covariância dos indicadores estudados, responsáveis pela determinação da correlação. Tais valores, para esse setor, apresentaram-se significativos, como, por exemplo, em 2010, o autovalor foi de 0,9910, em 2009 de 0,9863 e em 2008 e 2007, de 0,9943 e de 0,9916, respectivamente. Infere-se, nesse caso, que os indicadores do grupo A apresentam influência sobre os indicadores do grupo B.

Verifica-se, dessa forma, que existe forte relação entre a distribuição do valor adicionado aos agentes colaboradores e a lucratividade das empresas do setor de energia, pois a riqueza criada pela empresa e os salários e encargos dos funcionários apresentaram maiores coeficientes na equação da correlação.

Vale salientar que, quanto ao comportamento da relação entre as variáveis e o período, observou-se que os coeficientes de correlação apresentaram alta intensidade e que o setor de indústria de construção, seguido por bens de consumo, manifestaram coeficientes de correlação canônica mais baixos. Tal fato foi interessante tendo em vista que o setor de indústria de construção é um dos setores com desenvolvimento mais acentuado nos últimos anos (COSTA; NASCIMENTO, 2011). Apesar deste crescimento setorial, pode-se perceber que o mesmo está acompanhado da diminuição da distribuição da lucratividade para os colaboradores que contribuíram, direta ou indiretamente, para o alcance do melhor desempenho empresarial.

Resgatam-se, portanto, as concepções advindas de outros estudos acerca da distribuição do valor adicionado à empresa. Estudos anteriores defendem o desenvolvimento da DVA visando não somente a obrigatoriedade de demonstrar a riqueza criada, mas as possibilidades de análise inerentes à referida demonstração (MORLEY, 1979; RUTHERFORD, 1980; MCLEAY, 1983; BURCHELL; CLUBB; HOPWOOD, 1985; DE LUCA, 1998; RIAHI-BELKAOUI, 1999; CUNHA, 2002; SANTOS, 2007; VAN STADEN, 2007).

Adicionalmente, observa-se que a evidenciação e a análise da DVA permitem identificar o comprometimento dos colaboradores e a postura da administração no processo de gestão empresarial. As empresas participantes do ranking da Revista Exame Maiores e Melhores, como observado nos resultados da presente pesquisa, apresentaram a lucratividade correlacionada à distribuição do valor adicionado aos agentes colaboradores na formação da riqueza em todos os setores pesquisados. Tal resultado sugere que as empresas estão empreendendo esforços para reconhecer o esforço dos seus colaboradores na conquista de resultados, como defendido por Riahi-Belkaoui (1999), ao afirmar que a empresa pode proporcionar um bônus de produtividade aos colaboradores bem com contribuir para seu próprio processo de gestão. Além disso, Martins (2000) ressalta que a distribuição do valor adicionado aos agentes colaboradores possibilita diversas oportunidades tanto para a empresa quanto para os colaboradores, quanto às discussões colocadas pela atual dinâmica da economia internacional, que demanda maior qualificação profissional, polivalência, gestão participativa e maior comprometimento do trabalhador com os objetivos empresariais. 
Logo, verifica-se que há forte relação entre a distribuição do valor adicionado dos agentes colaboradores e a lucratividade, indicando que as empresas distribuem na medida em que obtém lucratividade em todos os setores pesquisados, sendo de forma mais intensa nos setores de energia, varejo, química e petroquímica, produção agropecuária e atacado, e de forma menos intensa nos setores de indústria de construção e bens de consumo.

\section{CONSIDERAÇÕES FINAIS}

O estudo objetivou identificar a correlação da distribuição do valor adicionado aos agentes colaboradores na formação da riqueza e a lucratividade das empresas. Para tanto foi desenvolvida uma pesquisa descritiva, com as formas de distribuição do valor adicionado aos agentes colaboradores, verificando o poder de correlação dessa distribuição.

Resgata-se a indagação que norteia o desenvolvimento da pesquisa: qual é a correlação entre o valor adicionado distribuído aos agentes colaboradores na formação da riqueza e a lucratividade das empresas? Em resposta a esta indagação, foi possível constatar que, dentre os setores econômicos analisados, o setor de atacado apresentou maior correlação em 2008, sendo esta de 99,42\%, se comparado aos anos de 2007, 2009 e 2010. Fato este que demonstra a influência entre os indicadores analisados nos respectivos Grupos A e B, com a distribuição do valor adicionado aos agentes colaboradores com a lucratividade das empresas deste setor. Isso se justifica por este setor ter apresentado no ano de 2008 os maiores coeficientes na equação da correlação para os indicadores de riqueza criada e salários e encargos dos colaboradores.

Os setores econômicos relacionados ao consumo e energia, também apresentaram a maior correlação no ano de 2008 , sendo de $94,42 \%$ e 99,71\%, respectivamente, apresentando forte influência dos Grupos A e B. A maior correlação canônica apresentada para o setor de produção agropecuária foi em 2009 com um percentual de 94,98\% de correlação se comparado aos demais anos analisados. Já o setor de química e petroquímica e varejo apresentaram forte correlação no ano de 2007 , sendo que para o primeiro o percentual foi de $94,48 \%$ e para o varejo $99,24 \%$. Constata-se, portanto, que estes setores também apresentaram influência na distribuição do valor aos agentes e a lucratividade.

E a indústria de construção em 2010 apresentou a maior correlação se comparada aos demais anos, sendo esta de $96,41 \%$, o que influência na distribuição do valor adicionado. Analisando os coeficientes da equação de correlação, percebe-se que os indicadores de riqueza criada e salários e encargos apresentaram maior coeficiente e, consequentemente, maior influência na distribuição.

Conclui-se, portanto, que houve alto valor de correlação entre os Grupos A e B, para todos os setores estudados, comprovando a influência entre os indicadores com a distribuição do valor adicionado aos agentes colaboradores e a lucratividade das empresas. Com o propósito de dar continuidade às pesquisas relacionadas à DVA, recomenda-se que estudos futuros sejam aplicados em outros setores econômicos, bem como utilizando outros indicadores econômicos e financeiras para comparar os resultados.

\section{REFERÊNCIAS}

$\mathrm{BAO}, \mathrm{B}-\mathrm{H} ; \mathrm{BAO}, \mathrm{D}-\mathrm{H}$. The time series behavior and predictivity-ability results of annual value added data. Journal of Business Finance \& Accounting, v. 23, n. 3, April 1996.

BENS, D.; MONAHAN, S. Disclosure quality and excess value of diversification. Journal of Accounting Research, v. 42, p. 691-730, 2004.

BENTLEY, T. Added value and contribution. Management Accounting, v. 59, n. 3, March, p. 17-21, 1981. 
BISPO, J. S. Criação e distribuição de riqueza pela Zona Franca de Manaus. São Paulo, 2009. Tese (Doutorado) Faculdade de Economia, Administração e Contabilidade da Universidade de São Paulo, 2009.

BOSCOV, C.; BISPO, J. S. A comparação da distribuição de riqueza gerada entre os setores de serviço, comércio e indústria. ConTexto, Porto Alegre, v. 10, n. 17, p. 59-70, 2010.

BRAGA, P. T. S. Demonstração do Valor Adicionado: um estudo comparativo do perfil de distribuição de riqueza pelas empresas estatais e privadas do Brasil. 98f. Dissertação (Mestrado em Ciências Contábeis) Programa Multiinstitucional e Interregional de Pós-Graduação em Ciências Contábeis (UnB, UFPB, UFRN). 2008.

BURCHELL, S. CLUBB, C. HOPWOOD, A. G. Accounting in its social context: towards a history of value added in the United Kingdom. Accounting Organizations and Society, v. 10, n. 4, p. 382-413, 1985.

CHAN, B. L.; SLOMSKI, V.; MARTINS, G. A. . Distribuição do Valor Adicionado: Comparação Entre Empresas Estatais e Privadas do Setor de Serviços Públicos. RAC, v. 11, n. 4, p. 199-218, 2007.

CHAN, B. L; MARTINS, G. A.; SLOMSKI, V. Distribuição do valor adicionado: comparação entre empresas estatais e privadas do setor de serviços públicos. In: 3ํ․ Congresso USP de Controladoria e Contabilidade, 2003. Anais... São Paulo, 2003.

CHAN, B. L.; SILVA, F. L.; MARTINS, G. A. Destinação de riqueza aos acionistas e as empregados: comparação entre empresas estatais e privadas. RAC, v.11, p. 199-218, 2007.

COSENZA, J. P. A Eficácia Informativa da Demonstração do Valor Adicionado. Revista Contabilidade E Finanças, Ano 14, Edição Comemorativa, 2003.

COSTA, D. D.; NASCIMENTO, P. T. S. A gestão do desenvolvimento de produtos na indústria de materiais de construção. Rev. Adm. Contemp. [online], v.15, n.1, p. 1-24, 2011.

CPC. Pronunciamento Técnico n. 9. Demonstração do Valor Adicionado. 2008. Disponível em: http://www.cpc.org.br. Acesso em 10 ago. 2011.

CUNHA, J. V. A. da. Demonstração contábil do valor adicionado - DVA - um instrumento de mensuração da distribuição da riqueza das empresas para os funcionários. São Paulo, 2002. Dissertação (Mestrado) Faculdade de Economia, Administração e Contabilidade da Universidade de São Paulo, 2002.

CUNHA, J. V. A.; RIBEIRO, M. S.; SANTOS, A. dos. A demonstração do valor adicionado como instrumento de mensuração da distribuição da riqueza. Revista Contabilidade e Finanças, São Paulo, n. 37, p. 7-23, jan/abr. 2005.

DALMÁCIO, F. Z. Indicadores para análise da demonstração do valor adicionado. Revista Brasileira de Contabilidade. Brasília, setembro/outubro 2004, n. 149, p. 89-97, 2004. 
DE LUCA, M. M. M. Demonstração do Valor Adicionado. Dissertação (Mestrado em Contabilidade e Controladoria). Faculdade de Economia, Administração e Contabilidade, Universidade de São Paulo, 1991.

DE LUCA, M. M. M. A contribuição da demonstração do valor adicionado no processo de mensuração do PIB e em algumas análises macroeconômicas. Tese (Doutorado em Contabilidade e Controladoria) Faculdade de Economia, Administração e Contabilidade, Universidade de São Paulo, 1996.

DE LUCA, M. M. M.; CUNHA, J. V. A., RIBEIRO, M. S., OLIVEIRA, M. C. Demonstração do Valor Adicionado: do cálculo da riqueza criada pela empresa ao valor do PIB. São Paulo. $2^{2}$ edição Editora Atlas. 2009.

FREGONESI, M. S. F. A. Investimentos socioambientais na demonstração do valor adicionado: formação ou distribuição do valor adicionado? São Paulo, 2009. Tese (Doutorado) Faculdade de Economia, Administração e Contabilidade, Universidade de São Paulo, 2009.

GALLO, M. F.; PEREIRA, C. A.; LIMA, E. M. Mensuração da carga tributária efetiva: existem divergências entre os enfoques econômico e contábil? In: Encontro da Anpad, 30, 2006, Salvador. Anais... São Paulo: Anpad, 2006.

HASHIMOTO, H.; SANTOS, A. dos. Demonstração do valor adicionado: algumas considerações sobre carga tributária. Revista de Administração da USP, São Paulo, v. 38, n. 2, p.153-164, 2003.

HAIR JR., J. F.; ANDERSON, R. E.; TATHAM, R. L.; BLACK, W. C. Análise multivariada de dados. Porto Alegre. 5ª edição: Bookman, 2005.

HENDRIKSEN, E. S.; BREDA, M. F. Teoria da contabilidade. São Paulo: Atlas, 1999.

KROETZ, C. E.; COSENZA, J. P. Considerações sobre a eficácia do valor adicionado para a mensuração do resultado econômico e social. In: Convenção de Contabilidade do Rio Grande do Sul, 4, Gramado. Anais... Gramado, 2003.

LIMA, M.A. Uma contribuição ao estudo sobre a elaboração do balanço social em entidades do terceiro setor: um estudo de caso. Dissertação (Mestrado em Controladoria e Contabilidade). Faculdade de Economia, Administração e Contabilidade, Universidade de São Paulo, 2003.

MACHADO, E. A.; MORCH, R. B.; VIANNA, D. S. C.; DOS SANTOS, R; DE SIQUEIRA, J. R. M. Destinação de riqueza aos empregados no Brasil: comparação entre empresas estatais e privadas do setor elétrico (2004-2007). Revista Contabilidade E Finanças - USP, São Paulo, v. 20, n. 50, p. 110122, 2009.

MEEK, G. K.; GRAY, S. J. The value added statement: an innovation for US companies? Accounting Horizons, v. 2, n. 2, June 1988, p. 73-81, 1988.

MCLEAY, S. Value Added: A comparative study. Accounting, Organizations and Society, v. 8, n. 1, p. 31-56, 1983. 
MORCH, R. B.; ALMEIDA, E.; DE ALMEIDA, L. B.; MARQUES, J. A. V. C. A Demonstração do Valor Adicionado como instrumento de análise do impacto tributário para as empresas do setor elétrico. Revista de Informação Contábil - RIC, v. 2, n. 4, p. 1-16, 2008.

MORLEY, M. The value added statement in Britain. The Accounting Review, v. 54, n. 3, p. 618-629, 1979.

MORAES, P. B. Uso da demonstração de valor adicionado como ferramenta de mensuração dos tributos de empresas selecionadas do Brasil. Dissertação (Mestrado em Gestão de Negócios) Universidade Católica de Santos, São Paulo, 2008.

PINTO, E.F. Valor Adicionado do setor elétrico: uma contribuição das empresas do setor na formação de riquezas. Dissertação (Mestrado interunidades do setor de energia) Programa Interunidades do Setor de Energia, Universidade de São Paulo, 2003.

PONG, C.; MITCHELL, F. Accounting for a Disappearance: A Contribution to the History of the Value Added Statement in the UK. The Accounting Historians Journal, v.32, n.2, p. 173-199, 2005.

RAO, P. M. Value Added Reporting: In Theory, Practice and Research. New Delhi/India: Deep \& Deep Publications, 2001.

REVISTA EXAME MAIORES E MELHORES. 2011. Critérios para os indicadores utilizados para análise de desempenho e os termos contábeis utilizados. Disponível em: http://www.cpc.org.br. Acesso em 26 out. 2011.

RIAHI-BELKAOUI, A. Value added reporting and research: state of the art. Westport, Connecticut London: Quorum Books, 1999.

RIAHI-BELKAOUI, A.; FREKAT, M. A. The magic in value added: merits of derived accounting indicator numbers. Managerial Finance, v. 20, n. 9, 1994. ABI/INFORM Global, p. 3.

RIAHI-BELKAOUI, A.; PICUR, R. D. Net value added as an explanatory variable for returns. Managerial Finance, v. 20, n. 9, 1994, ABI/INFORM Global, p. 56.

RUTHERFORD, B. A. Published Statements of value added: a survey of three years' experience. Accounting and Business Research, Winter, 1980.

RODRIGUES JÚNIOR, M. S. A DVA como Instrumento para Mensuração da Relação CustoBenefício na Concessão de Incentivos Fiscais: Um Estudo de Caso. In: ENCONTRO ANPAD, 27, São Paulo, Atibaia, 2003. Anais... Enanpad: Atibaia, 2003.

SANTOS, A. Demonstração contábil do valor adicionado - DVA: um instrumento para medição da geração e distribuição de riqueza das empresas. Tese (Livre docência). Faculdade de Economia, Administração e Contabilidade, Universidade de São Paulo, 1999.

SANTOS, A. Demonstração do Valor Adicionado. São Paulo: Atlas, 2003. 
SANTOS, A. Demonstração do valor adicionado: como elaborar e analisar a DVA. 2. ed. São Paulo: Atlas, 2007.

SANTOS, M. I. C.; Silva, M. S. Utilização da demonstração do valor adicionado - DVA como ferramenta na medição da riqueza no setor de telefonia no Brasil. Pensar Contábil, Rio de Janeiro, v. 11, n. 46, p. 39-45, 2009.

SANTOS, A.; CHAN, B. L.; DA SILVA, F. L. Análise dos impactos da privatização na distribuição de riqueza a partir da Demonstração do Valor Adicionado. Revista Universo Contábil - FURB, Blumenau, v. 3, n. 1, p. 06-21, 2007.

SILVEIRA, E. C. Demonstração do Valor Adicionado (DVA): uma análise da geração e distribuição de riqueza nas empresas de energia elétrica do Brasil (período: 1999 - 2001). Dissertação (Mestrado em Ciências Contábeis) Faculdade de Economia, Administração, Contabilidade e Ciência da informação e Documentação, Recife, 2003.

TINOCO, J. E. P.; MORAES, P. B. Uso da Demonstração do Valor Adicionado - DVA, como ferramenta de medição da carga tributária no Brasil. Revista eletrônica de Gestão de Negócios - eGesta, v. 4, n. 1, p. 1-32, 2008.

VAN STADEN, C. The usefulness of the value added statement in South Africa. Managerial Finance, v. 24, n. 11, 1998. ABIN/INFORM Global, p. 44.

VAN STADEN, C. The value added statement: bastion of social reporting or dinosaur of financial reporting? Massey Discussion Paper no. 200. Mar, 2000. Disponível em:

http://mro.massey.ac.nz/bitstream/handle/10179/2543/200.pdf?sequence=1. Acesso em: 12 abr.2012.

VAN STADEN, C. Revisiting the value added statement: social responsibility or manipulation? Critical Perspectives on Accounting Conference at Baruch College: City University New York, 25 - 27 April, 2007. Disponível em: http://aux.zicklin.baruch.cuny.edu/critical/html12/8109staden.html. Acesso em: 07 abr. 2012.

VICENTE, G.O. Distribuição do Valor Adicionado aos Recursos Humanos dos Bancos Localizados no Brasil, no Triênio 1998-2000: análise comparativa. Dissertação (Mestrado em Ciências Contábeis) Faculdade de Economia, Administração, Contabilidade e Ciência da informação e Documentação, Brasília, 2003.

VIEIRA, P. dos S.; SANTOS, A. dos. Um estudo empírico sobre a carga tributária das sociedades cooperativas agropecuárias a partir da demonstração do valor adicionado. In: CONGRESSO USP DE CONTROLADORIA E CONTABILIDADE, 7, 2007, São Paulo. Anais... FEA-USP: São Paulo, 2007.

ZAN, F.R. A Demonstração do valor adicionado como instrumento de verificação da geração de riqueza em cooperativas de agronegócio do Rio Grande do Sul. Dissertação (Mestrado) Programa de Desenvolvimento, Universidade Regional do Noroeste do Estado do Rio Grande do Sul, 2004. 